Naohiko Seki • Atsushi Hattori · Sumio Sugano

Masa-aki Muramatsu - Toshiyuki Saito

\title{
cDNA cloning, expression profile, and genomic structure of human and mouse RNF10/Rnf 10 genes, encoding a novel RING finger protein
}

Received: July 26, 1999 / Accepted: September 4, 1999

\begin{abstract}
RING finger (C3HC4-type zinc finger) is a variant zinc finger motif present in a new family of proteins including transcription regulators. A new member of the RING finger protein family was identified through a mouse expressed sequence tag (EST) database search, and its fulllength cDNA was isolated from a mouse brain full lengthenriched cDNA library. The gene was designated as Rnf10, for RING finger protein 10. The cDNA clone consists of 3110 nucleotides and encodes an open reading frame (ORF) of an 804-amino acid protein. A database search revealed that human KIAA0262 protein (accession number, D87451) has strong homology to mouse Rnf10. To confirm that mouse Rnf10 is the homolog or an isolog of human KIAA0262, a human RNF10 cDNA was cloned in our hands from a fetal brain cDNA pool. The newly isolated cDNA contained an ORF for 811 amino acids which had almost identical structure to mouse Rnf10 protein, indicating that the human ORF codes for RNF10 protein. This finding was also supported by comparative chromosome mapping in which both genes were localized in a conserved linkage homology region between mouse and human. Comparison of the RNF10 and KIAA0262 proteins revealed
\end{abstract}

N. Seki · A. Hattori · T. Saito $(\square)$

Genome Research Group, National Institute of Radiological

Sciences, Anagawa 4-9-1, Inage-ku, Chiba 263-8555, Japan

Tel. 181-43-206-3135 Fax 181-43-251-9818

e-mail: t_saito@nirs.go.jp

N. Seki $\cdot$ M. Muramatsu

Helix Research Institute, Kisarazu, Chiba, Japan/

S. Sugano

Department of Virology, the Institute of Medical Sciences,

University of Tokyo, Tokyo, Japan

M. Muramatsu

Department of Biological Cybernetics, Medical Research Institute, Tokyo Medical Dental University, Tokyo, Japan

The nucleotide sequence data of human RNF10 and mouse Rnf10 genes reported in this paper have been submitted to DDBJ, EMBL, and GenBank database and appear under the accession number AB027196 and AB026621, respectively. that both were transcribed from the same gene and that the longer RNF10 ORF would be the authentic form. The complete genomic organization of $R N F 10$ was determined to consist of 17 exons spanning at least $40 \mathrm{~kb}$ in the genome.

Key words RING finger (C3HC4-type zinc finger) motif RNF10 - Rnf10 - KIAA0262 - RH mapping · 12q23-q24.1 · D5Mit318

\section{Introduction}

Zinc finger motifs are composed of several subfamilies based on their different types of fingers categorized by the nature and spacing of their zinc-chelating residues (Schwabe and Klug 1994; Mackay and Crossley 1998). An increasing number of genes encoding zinc finger motifs is being identified in the course of genome sequencing projects, and to date zinc finger proteins constitute the largest gene superfamily (Tatusov et al. 1997; Neil et al. 1998). The RING finger, named after the Really Interesting New Gene 1 (Hanson et al. 1991), was originally identified as a cysteine-rich, putative zinc-chelating motif in otherwise unrelated proteins (Freemont et al. 1991). RING finger (C3HC4-type zinc finger) motif is a variant type of zinc finger motif and members of RING finger proteins can be divided into several groups according to their sequence homology, domain structure, and assumed biological functions (Freemont 1993; Saurin et al. 1996). Members of the RING finger family are implicated in a variety of functions, such as transcriptional regulation, DNA repair, site-specific recombination, and signal transduction (Freemont et al. 1991; Barlow et al. 1994; Borden et al. 1995; Saurin et al. 1996).

\section{Source and isolation of human and mouse RING finger protein genes RNF10/Rnf10}

Recently, we systematically isolated cDNA clones encoding a novel RING finger protein (Seki et al. 1998; Ueki et al.

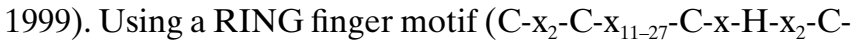
$\left.\mathrm{x}_{2}-\mathrm{C}-\mathrm{x}_{6-12}-\mathrm{C}-\mathrm{x}_{2}-\mathrm{C}\right)$ as a query sequence, we searched for the 
public mouse expressed sequence tag (EST) database with the tBLASTN program (www.ncbi.nlm.nih.gov/cgi-bin/ BLAST/nph-newblast?Jform = 1) and found a cluster of several ESTs with a RING finger motif (accession numbers, AA413547, AA117803, AA471771, AI115110). To obtain the full-length cDNA structure of the new RING finger protein gene, we performed polymerase chain reaction (PCR), using specific primers designed from the consensus sequences of these ESTs and vector primers. Several independent cDNA clones were isolated from a mouse brain full-length enriched cDNA library and sequenced by the dideoxy chain-termination method with an ABI377 DNA sequencer (Perkin Elmer, Norwalk, CT, USA) according to the supplier's instructions. The resultant consensus sequence was $3110 \mathrm{bp}$ in length and the presumed initiation methionine was preceded in the sequence by an in-frame stop codon. The open reading frame encoded a protein of 804 amino acids residues (Fig. 1) having a molecular mass of $100.5 \mathrm{kDa}$. The putative protein contained a canonical RING finger motif (CPICLYPPTAAKITRCGHIFCWACILHYLSLSEKTWSKCPIC) at the amino-terminal region (between residues $225 \mathrm{aa}$ and 266aa) (Fig. 1). A polyadenylation signal, AATAAA, was located $18 \mathrm{bp}$ upstream of the poly(A). Three putative nuclear localization signals, KRKRQRQKK (592aa-600aa), RRRERR (605aa-610aa), and KKRKKQKQK (785aa-793aa) existed (Fig. 1). We designated the gene as RING finger protein 10 (Rnf10 as the gene symbol approved by the Human Gene Nomenclature Committee). The nucleotide sequence data of mouse Rnflo cDNA will appear in the DDBJ, EMBL, and GenBank nucleotide sequence databases with the accession number, AB026621.

Rnf10 protein showed striking homology to human KIAA0262 protein (accession number, D87451). Then we determined the human RNF10 cDNA sequence by our hands to confirm whether mouse Rnf10 is the homolog or an isolog of human KIAA0262. The human EST database was searched with the Rnf10 amino acid sequence as a query with the tBLASTN program, and many ESTs were obtained as transcripts from the probable RNF10 gene. With primers designed from a consensus nucleotide sequence of the hit ESTs', 5' and 3'-RACE (rapid amplification of cDNA ends) were performed with a human fetal brain-derived RACE cDNA library (Clontech, Palo Alto, CA, USA). The obtained cDNA contained an 811amino acid open reading frame (ORF) which is entirely homologous to Rnf10 protein (91\% identity and 93\% similarity), indicating that the cDNA represents human RNF10, the counterpart of mouse Rnf10. Multiple alignment of RNF10, Rnf10, and KIAA0262 protein amino acid sequences is shown in Fig. 1. The KIAA0262 protein lacks 52 amino acid residues of amino terminal present in the RNF10/Rnf10 protein. Conservation of the N-terminal structure between human and mouse suggests that the cDNA sequence of RNF10 is authentic, although how the cDNA sequence of KIAA0262 is created (alternative form or any artifacts) is unknown. The approved symbol RNF10 for this human counterpart (accession number, AB027196) has been offered by Human Nomenclature Committee.
We examined the distribution of the mouse Rnf10 transcript in various mouse fetal and adult tissues by reverse transcription-coupled polymerase chain reaction (RTPCR). A clear common signal of the expected size was detected in all the tissues examined (data not shown), indicating that the mouse Rnflo gene is ubiquitously transcribed in various tissues and would be involved in the basic housekeeping function of cells. Such a ubiquitous expression profile has good accordance with the northern blot analysis of KIAA0262 (Nagase et al. 1996).

\section{Chromosome mapping of RNF10 and Rnf10 genes}

We determined the chromosomal location of the mouse Rnf10 gene using a radiation hybrid panel (T31 Mouse Radiation Hybrid Panel; Research Genetics, Huntsville, AL, USA) in the same manner as in previous reports (Saito et al. 1997; Seki et al. 1999). Primers used for PCR amplification correspond to the $3^{\prime}$ untranslated region of the gene $\left(5^{\prime}\right.$ AGG GGA AGC TGG AAA ATA CAC- $\left.3^{\prime}\right)$ and $\left(5^{\prime}\right.$-ACA GAT TGA TTA GCT TGG GGC-3') (95-bp PCR product). The radiation hybrid mapping data were processed using the RHMAPPER software package (http:// carbon.wi.mit.edu:8000/cgi-bin/contig/rhmapper.pl). The data vector for the gene was 00001211000001000000 $\begin{array}{llll}0100001001 & 0001000000 & 1000000010 & 0100000010\end{array}$ $0000001001000000111110000002001001100110(\operatorname{lod}>3.0)$ and the consequent statistical report indicated the gene was mapped to chromosome 5, with the nearest public locus the D5Mit318 region. This region contains homologous organization to the human chromosome 12q22-q24 region (www.ncbi.nlm.nih.gov/Homology). A search in the Unigene database (www.ncbi.nlm.nih.gov/UniGene/ Hs.Home.html) showed that human KIAA0262 (Hs.5094) was mapped to the chromosome 12q23-q24.1 region, with markers between D12S366 and D12S340. Thus, it was confirmed that the mouse Rnf10 and human RNF10 are localized in a region with conserved linkage homology among these species. These mapping data support the idea that the two genes are homologs of each other.

\section{Genomic structure of the human RNF10 gene}

Several members of the RING finger protein family are implicated in human diseases. For example, the RING finger protein, BRCA1, is a tumor suppressor in early onset breast cancer (Miki et al. 1994), and another member, PML, produces a fusion protein with the retinoic acid receptor alpha in acute promyelocytic leukemia (de The et al. 1991; Goddard et al. 1991; Kakizaki et al. 1991; Kastner et al. 1992), and the human 52-kDa SS-A/Ro RING finger protein is the nuclear antigen in Sjogren's autoimmune disease (Chan et al. 1991; Itoh et al. 1991). The chromosomal position, genomic structure, and expression profile of such genes may contribute to ongoing positional candidate ap- 
.Q...S. .

Fig. 1. Alignment of human RNF10 (accession number, AB027196), mouse Rnf10 (AB026621), and KIAA0262 (D87451) proteins. Asterisks denote the terminal codon. The potential RING finger-motif is double underlined, and putative nuclear localizing signals are underlined with a single line 
Table 1. Intron-exon boundaries of the human RNF10 gene

\begin{tabular}{|c|c|c|c|}
\hline Exon No. & Exon size $^{\mathrm{a}}$ & Splice acceptor ${ }^{\mathrm{b}}$ & Splice donor ${ }^{\mathrm{b}}$ \\
\hline 1 & 604 & & CCCAAGAGCG gtaaggacgggc \\
\hline 2 & 197 & tcttgctttcag ATGGAAAGAA & ACGAGATGAG gtatggaatttg \\
\hline 3 & 200 & cattctctctag GTAGCAGAGG & TACAGGCCAA gtgagtattgct \\
\hline 4 & 91 & tcctatttctag CTGCCAATTT & GGAACAAGTG gtgagtagctca \\
\hline 5 & 185 & attttgtttcag CGCATTTGTA & ATCTCAAGAG gtgagattgaga \\
\hline 6 & 137 & tccatgtttcag TGTTGTTGCC & CATCTAGGAG gtgagttcttta \\
\hline 7 & 161 & gcattcttatag ATGAACAGCA & GGAGCTCAAG gtgagaggatgc \\
\hline 8 & 126 & tggccacgttag ACTCGGGAAG & ACCCAGGAAG gttagtgtgtcC \\
\hline 9 & 277 & ttgctgcaacag GGTGTGCTGG & TTTTACCAAG gtgagggtgccg \\
\hline 10 & 134 & ccttgtcctcag CGGAAGATGG & CATGTCTGAG gtgaggecttcC \\
\hline 11 & 118 & tttccaatgtag GATGTTCGAC & ATGTTCTCAG gtgagaatgcсC \\
\hline 12 & 102 & accaatctgcag ATGACATTGA & CAGGGCAAGT gtaagttcagga \\
\hline 13 & 156 & tttcctttgcag ACCCAGAAGT & TCCCATGCAG gtaaacaggtga \\
\hline 14 & 101 & gttccctttcag ACTTTCTGCT & CTTTGCCCAG gtaaatcctttg \\
\hline 15 & 58 & ccactttggcag ATGCTGAGGG & CCAAAGAAAG gtgaggatggtc \\
\hline 16 & 159 & ggtattttttag ATGAGAACAG & ССССтСтCтG gtaagggcagag \\
\hline 17 & 298 & gtctccctttag AAGAGAAAGG & \\
\hline
\end{tabular}

Intron-exon junctions were established by comparison of cDNA and genomic sequences

${ }^{a}$ Size in basepairs

${ }^{\mathrm{b}}$ Sequences at the splice junction. Exonic sequences are shown in capital letters, with intronic sequences shown in lowercase letters. Invariant nucleotides (ag/gt) are in boldface type

proaches for disease genes linked to the genomic locus.

Sequences of the exon-intron boundaries of the gene were identified by aligning the cDNA sequence with a genomic sequence (Accession numbers, AL022340, Z97199). As summarized in Table 1, all the splicing sites conformed to the AG-GT rule, in that there are always AG and GT dinucleotides at the splice acceptor and donor sites, respectively. The RNF10 gene is divided into 17 exons, which range in size from $58 \mathrm{bp}$ (exon 15) to $604 \mathrm{bp}$ (exon 1 ). The first exon is $604 \mathrm{bp}$ and it contains the putative ATG start codon. The last exon of $298 \mathrm{bp}$ contains the TAG translation termination codon followed by a 221-bp $3^{\prime}$ untranslated region. The genome structure of the RNF10 gene, consisting of 17 exons, spans approximately $40 \mathrm{~kb}$ of the genome DNA.

\section{References}

Barlow PN, Luisi B, Milner A, Elliott M, Everett R (1994) Structure of the $\mathrm{C} 3 \mathrm{HC} 4$ domain by $1 \mathrm{H}$-nuclear magnetic resonance spectroscopy. A new structural class of zinc-finger. J Mol Biol 237:201-211

Borden KL, Boddy MN, Lally J, O'Reilly NJ, Martin S, Howe K, Solomon E, Freemont PS (1995) The solution structure of the RING finger domain from the acute promyelocytic leukaemia protooncoprotein PML. EMBO J 114:1532-1541

Chan EK, Hamel JC, Buyon JP, Tan EM (1991) Molecular definition and sequence motifs of the $52-\mathrm{kD}$ component of human SS-A/Ro autoantigen. J Clin Invest 87:68-76

de The H, Lavau C, Marchio A, Chomienne C, Degos L, Dejean A (1991) The PML-RAR alpha fusion mRNA generated by the $t(15 ; 17)$ translocation in acute promyelocytic leukemia encodes a functionally altered RAR. Cell 66:675-684

Freemont PS, Hanson IM, Trowsdale J (1991) A novel cysteine-rich sequence motif. Cell 64:483-484

Freemont PS (1993) The RING finger. A novel protein sequence motif related to the zinc finger. Ann N Y Acad Sci 684:174-192

Goddard AD, Borrow J, Freemont PS, Solomon E (1991) Characterization of a zinc finger gene disrupted by the $t(15 ; 17)$ in acute promyelocytic leukemia. Science 254:1371-1374

Hanson IM, Poustka A, Trowsdale J (1991) New genes in the class II region of the human major histocompatibility complex. Genomics 10:417-424

Itoh K, Itoh Y, Frank MB (1991) Protein heterogeneity in human Ro/ SSA ribonucleoproteins. J Clin Invest 87:117-186

Kakizuka A, Miller WH Jr, Umesono K, Warrell RP Jr, Frankel SR, Murty VV, Dmitrovsky E, Evans RM (1991) Chromosomal translocation $\mathrm{t}(15 ; 17)$ in human acute promyelocytic leukemia fuses RAR alpha with a novel putative transcription factor, PML. Cell 66:663-674

Kastner P, Perez A, Lutz Y, Rochette-Egly C, Gaub MP, Durand B, Lanotte M, Berger R, Chambon P (1992) Structure, localization and transcriptional properties of two classes of retinoic acid receptor alpha fusion proteins in acute promyelocytic leukemia (APL): structural similarities with a new family of oncoproteins. EMBO J 11:629-642

Mackay JP, Crossley M (1998) Zinc finger are sticking together. Trends Biochem Sci 23:1-4

Miki Y, Swensen J, Shattuck-Eidens D, Futreal PA, Harshman K, Tavtigian S, Liu Q, Cochran C, Bennett LM, Ding W, Yshio Miki, Jeff Swensen, Donna Shattuck-Eidens, P. Andrew Futreal, Keith Hrashman, Sean Tavigian, Qingyun Liu, Charles Cochran, L. Michelle Bennet, wei Ding, Russel Bell, Judith Rosenthal, Charles Hussey, Thanh Tran, Melody McClure, Cheryl Frye, Tom Hattier, Robert Phelps, Astrid Haugen-Strano, Harold Katcher, Kazuko Yakumo, Zahra Gholami, Daniel Shaffer, Steven Stone, Steven Bayer, Christian Wray, Robert Bodgen, Priya Dayananth, John Ward, Patricia Tonin, Steven Narod, Pam K. Brisow, Frank H. Norris, Leah Helvering, Paul Morrison, Paul Rosteck, Mei Lai, J. Carl Barrett, Cathryn Lewis, Susan Neuhausen, Lisa CannonAlbright, David Goldgar, Roger Wiseman, Alexander Kamb, Mark H. skolnick (1994) A strong candidate for the breast and ovarian cancer susceptibility gene BRCA1. Science 266:66-71

Nagase T, Seki N, Ishikawa K, Ohira M, Kawarabayasi Y, Ohara O, Tanaka A, Kotani H, Miyajima N, Nomura N (1996) Prediction of the coding sequences of unidentified human genes. VI. The coding 
sequences of 80 new genes (KIAA0201-KIAA0280) deduced by analysis of cDNA clones from cell line KG-1 and brain. DNA Res 3:321-329

Neil D, Clarke ND, Berg JM (1998) Zinc fingers in Caenorhabditis elegans: finding families and probing pathways. Science 282:2018-2022

Saito T, Seki N, Ishii H, Ohira M, Hayashi A, Kozuma S, Hori T (1997) Complementary DNA cloning and chromosomal mapping of a novel phosphatidylinositol kinase gene. DNA Res. 4:301-305

Saurin AJ, Borden KL, Boddy MN, Freemont PS (1996) Does this have a familiar RING? Trends Biochem Sci $121: 208-214$

Schwabe JW, Klug A (1994) Zinc mining for protein domains. Nat Struct Biol 1:345-349

Seki N, Hattori A, Sugano S, Suzuki Y, Nakagawara A, Ohhira M,
Muramatsu M, Hori T, Saito T (1998) Isolation, tissue expression, and chromosomal assignment of a novel human gene which encodes a protein with RING finger motif. J Hum Genet 43:272-274

Seki N, Hattori A, Hayashi A, Kozuma S, Ohira M, Hori T, Saito T (1999) Structure, expression profile and chromosomal location of an isolog of DNA-PKcs interacting protein (KIP) gene. Biochim Biophys Acta 1444:143-147

Tatusov RL, Koonin EV, Lipman DJ (1997) A genomic perspective on protein families. Science 278:631-637

Ueki N, Seki N, Yano K, Ohira M, Saito T, Masuho Y, Muramatsu M (1999) Isolation and characterization of a novel human gene (HFB30) which encodes a protein with a RING finger motif. Biochim Biophys Acta 1445:232-236 